ARTIKEL

Filsafat Politik Nurcholish Madjid

Muhammad Saleh Tajuddin

Kedaulatan Rakyat dalam Pemikiran Filsafat

Politik Montesquieu

Fajrul Ilmy Darussalam \& Andi Batara Indra

$189-204$

Politik Multikulturalisme: Sebuah Gerakan Keadilan

dan Kesetaraan

Muhaemin Latif

$205-229$

Kompetisi, Kompromi dan Coalition Agreement: Berebut

Kursi Wakil Gubernur DKI Jakarta di Tengah

Kontestasi Pemilihan Presiden 2019

Mahpudin \& Fransisca Mega Lestari

$230-259$

Kegagalan Keterlibatan Politik: Dari Kesenjangan Digital

Menuju Kesenjangan Demokrasi

Fairuz Arta Abhipraya \& Bambang Eka Cahya Widodo

Mobilisasi Massa Kemenangan Kolom Kosong Pada Pemilihan Walikota Makassar Tahun 2018

Gustiana Kambo

Kinerja Komisi Pemilihan Umum Kota Makassar dalam

Melindungi Hak Pilih Warga di Tengah

Pandemi COVID-19

Dyahwanti Sulistyowati, Muhammad, Sukri \& Ariana

Isu Pemekaran Wilayah Sebagai Komoditas Politik Dalam Masyarakat

To Pulo di Kepulauan Selayar

Dwi Indriani \& Sudarmono

Penanganan Konflik Melalui Keamanan di Kalimantan Barat 


\title{
PENANGANAN KONFLIK MELALUI KEAMANAN DI KALIMANTAN BARAT
}

\author{
Elyta \\ Universitas Tanjungpura \\ Email: elyta@fisip.untan.ac.id
}

\begin{abstract}
Abstrak
Kabupaten Pontianak termasuk daerah rawan konflik dengan catatan telah terjadi sebanyak 24 konflik di daerah tersebut hingga tahun 2014. Tujuan penelitian ini ialah untuk mengetahui dan menganalisis bagaimana penanganan konflik terhadap keamanan di Kabupaten Pontianak, Kalimantan Barat, Indonesia. Penelitian ini merupakan penelitian kualitatif dengan pengumpulan data melalui observasi langsung dan wawancara terbuka dengan informan kunci. Berdasarkan hasil penelitian diketahui bahwa konflik yang terjadi disebabkan antara lain tentang tata batas yang terjadi di masyarakat, konflik investasi-perkebunan antara masyarakat dengan perusahaan, konflik politik antar masyarakat setempat dan pemerintah. Pola penanganan yang melibatkan partisipasi masyarakat luas dengan mendayagunakan kearifan lokal menjadi upaya lain terhadap penanganan konflik ini. Melalui kerjasama antar aktor yang terlibat di dalamnya dan pendayagunaan kearifan lokal tersebut diharapkan konflik dapat ditangani dan membawa dampak positif.
\end{abstract}

\section{Kata Kunci:}

Penanganan Konflik, Keamanan, Kearifan Lokal

\begin{abstract}
Pontianak which is located in West Kalimantan, Indonesia, is considered as a conflictprone area with 24 conflicts that happened until 2014. The purpose of this study is to determine and analyze how conflict is resolved in Pontianak. This research is qualitative research with data collection through direct observation and open interviews with key informants. Based on the results of the study, it is found that the prime reasons for conflict are boundaries dispute among the local communities, investment-plantation conflicts between the community and companies, political conflicts between local communities and the government. Regarding conflict management, the adoption of local wisdom values becomes the main important aspect in overcoming conflict. Through cooperation between the actors involved combined with the local value among the society, conflicts should be handled and it brings positive impact.
\end{abstract}

Keywords:

Conflict Management, Security, Local Wisdom 


\section{Pendahuluan}

Di era globalisasi yang pesat saat ini, negara harus mampu menyaring proses globalisasi yang berpotensi menjadi ancaman bagi perekonomian negara. ${ }^{1}$ Analisis dampak ekonomi dari konflik dan kekerasan di negara berkembang seperti Kolombia, India dan Sierra Lione, dapat menghancurkan persediaan modal suatu negara, kualitas tenaga kerja serta ketergantungan operasional perusahaan. ${ }^{2}$ Solusi atas upaya peningkatan pertumbuhan pembangunan berkelanjutan, konflik bersenjata antar suku dapat direduksi dengan mekanisme kesetaraan antar suku, termasuk pemberian hak kelompok, pembagian kekuasaan pemerintahan dan daerah, demokrasi dan upaya internasional, termasuk pemeliharaan keamanan. Hal ini juga dapat didukung dengan upaya mendorong pembangunan ekonomi dan kapasitas negara. ${ }^{3}$

Konflik yang terjadi di Indonesia lebih didominasi oleh konflik antar suku, seperti di Kalimantan Barat tahun 1999 yang menimbulkan kerugian, baik besarnya angka kematian hingga kerugian materil dan trauma. Di Indonesia, terdapat peningkatan kasus dari 12\% pada rentang tahun 1990-1995 menjadi 67\% pada tahun 1997-2014 dengan persentase tertinggi terjadi antara tahun 1997-2002. Pada tahun 1997, konflik komunal antara Dayak dan Madura di Kalimantan Barat menyebabkan 4.500 korban jiwa dan 670.000 orang hilang. ${ }^{4}$

Secara historis, beberapa konflik yang tercatat di Kabupaten Pontianak dapat ditelusuri lebih jauh ke belakang. Misalnya pada tahun 1968 terjadi konflik antara suku Dayak dan suku Madura di Anjongan yang dipicu karena pembunuhan. Konflik serupa kemudian terjadi pada tahun 1976 di Sungai Pinyuh dan pada tahun 1983 di Sungai Enau, Kecamatan Sungai Ambawang. Selain faktor konflik antar etnis, beberapa tahun

${ }^{1}$ Martoyo, Elyta, Herlan Herlan \& Arifin Arifin, "Economic Development and Sustainable Human Resources by Supply Chain Managament in Government Towards in West Kalimantan Indonesia" dalam International Journal Of Supply Chain Managament, Vol. 9, No. 1 (2020), h. 10541063.

${ }^{2}$ Tilman Brück, Wim Naudé \& Philip Verwimp, "Business Under Fire: Entrepreneurship and Violent Conflict in Developing Countries" dalam Journal of Conflict Resolution, Vo. 57, No. 1 (2012), h. $3-19$.

${ }^{3}$ Lars-erik Cederman \& Yannick Pengl, "Global Conflict Trends and Their Consequences" dalam Background Paper to the United Nations Sustainable Development Outlook (2019), h. 1-55.

${ }^{4}$ Sujarwoto, "Geography and Communal Conflict in Indonesia" dalam Indonesian Journal of Geography, Vol. 49, No. 1 (2017), h. 89-96. 
belakangan konflik mulai merambah pada ranah antar ormas keagamaan. ${ }^{5}$ Lebih terbaru menunjukkan bahwa konflik masih saja terjadi di Kabupaten Pontianak jika melihat data dari Polisi Resor Kabupaten Pontianak, sebagaiman tabel di bawah:

Tabel 1.

Konflik di Kabupaten Pontianak

\begin{tabular}{|c|c|c|}
\hline No. & Lokasi (Kecamatan) & Jumlah Kasus \\
\hline 1. & Sei kunyit & 1 \\
\hline 2. & Sei Pinyuh & 4 \\
\hline 3. & Anjongan & 6 \\
\hline 4. & Mempawah Timur & 6 \\
\hline 5. & Siantan & 5 \\
\hline 6. & Mempawah Hilir & 1 \\
\hline 7. & Segedong & 1 \\
\hline \multicolumn{2}{|c|}{} & Total \\
\hline
\end{tabular}

Sumber: Polres Kabupaten Pontianak, 2014.

Dari data tersebut menggambarkan Kabupaten Pontianak termasuk daerah rawan terjadinya eskalasi konflik di Kalimantan Barat. Tercatat pula bahwa peran aktif Pemerintah Daerah sebagai mediator antar kelompok masyarakat yang bertikai belum maksimal. Maka perlu dilakukan penelitian terkait bagaimana penanganan konflik terhadap keamanan di Kabupaten Pontianak, Kalimantan Barat, Indonesia.

\section{Tinjauan Pustaka}

Penelitian sebelumnya telah dilakukan terkait konflik yang terjadi antar komunitas termasuk penelitian yang dilakukan di wilayah Ghana, Afrika, yaitu tentang konflik sengketa tanah. ${ }^{6}$ Konflik batas antar komunitas merupakan tantangan utama bagi tata kelola lahan di sub-Sahara Afrika termasuk Ghana. Meskipun pengecualian yang ditimbulkan oleh konflik batas antar komunitas biasanya mempengaruhi banyak orang, penelitian empiris sebagian besar berfokus pada perampasan tanah skala besar. Penelitian ini menggunakan metode wawancara mendalam untuk mengkaji aspek

${ }^{5}$ Kristianus, "Nasionalisme Etnik Di Kalimantan Barat" dalam Masyarakat Indonesia, Vol. 37, No. 2 (2011), h. 147-176.

${ }^{6}$ Moses Mosonsieyiri Kansanga, Godwin Arku \& Isaac Luginaah, "Powers of Exclusion and Counter-Exclusion: The Political Ecology of Ethno-Territorial Customary Land Boundary Conflicts in Ghana" dalam Land Use Policy, Vol. 86, Issue C (2019), h. 12-22. 
pendorong yang mendasari, strategi eksklusi dan kontra-eksklusi yang dilakukan oleh kelompok-kelompok yang bersengketa dan membuat rekomendasi kebijakan untuk menyelesaikan tanah adat.

Penelitian selanjutnya dilakukan di Pakistan dan khususnya Asia Selatan tentang masalah kerawanan keamanan lingkungan yang dapat menimbulkan konflik antar negara di Asia Selatan. ${ }^{7}$ Tantangan lingkungan, seperti perubahan iklim, kelangkaan air dan ketahanan energi membentuk pola pembangunan dan konsumsi, yang merupakan kemungkinan penyebab konflik antar negara di Asia Selatan. Pada penelitian tersebut menemukan bahwa diperlukannya integrasi pembangunan dengan faktor lingkungan dan keamanan yang berpotensi untuk mencapai pembangunan berkelanjutan di Asia Selatan.

Pada penelitian kali ini, peneliti ingin menganalisis penanganan konflik terhadap keamanan di Kabupaten Pontianak dengan memiliki kebaruan yakni pada penggunaan metode penilaian cepat yang digunakan agar dapat secara selektif mengidentifikasi penerapannya secara khusus sesuai dengan fenomena yang diteliti.

\section{Penanganan Konflik}

Konflik merupakan pertentangan antar individu yang disebabkan oleh ketidaksamaan pikiran, tingkah laku, gagasan, kepentingan, persyaratan, serta dalam beberapa kasus yakni prasangka. Hal tersebut menghasilkan pertengkaran yang memanas, pelecehan fisik, dan tidak diragukan lagi, hilangnya kedamaian dan harmoni. Hubungan dapat diubah oleh konflik. Konflik bisa muncul tidak hanya antar individu, namun dapat pula terjadi antar negara, antar partai dan antar kelompok etnis. Konflik dapat menyebabkan keresahan dan ketidakharmonisan besar jika tidak dapat dikendalikan sejak awal. Konflik dapat terjadi dalam berbagai bentuk perkataan, keagamaan, emosionali, sosial-teritorial, individu dan organisas/komunitas.

Secara tradisional konflik dianggap muncul dari kepentingan yang berlawanan yang melibatkan sumber daya yang langka, divergensi tujuan dan frustrasi. Konflik sering kali disalahartikan sebagai negatif dan merusak. Namun demikian, terdapat bukti

${ }^{7}$ Mabroor Hassan, Manzoor Khan Afridi \& Muhammad Irfan Khan, "Environmental Diplomacy in South Asia: Considering the Environmental Security, Conflict and Development Nexus" dalam Geoforum, Vol. 82 (2017), h. 127-130. 
substansial yang menunjukkan hasil positif dari konflik yang dikelola dengan baik. Konflik acapkali terjadi dikarenakan adanya ego untuk memenangkan kepentingan masing-masing pihak.

Konflik bersifat kompleks karena minimal melibatkan interaksi dinamika kognitif, psikologis, fisiologis, dan kontekstual. Kebanyakan teori konflik hanya mengambil pendekatan psikologis atau ekonomi untuk memahami dan mengelola konflik. Konflik tidak dapat diselesaikan jika tidak memahami penyebab konflik terlebih dahulu. Hanya ketika diagnosis berkembang menjadi istilah konkret, barulah dapat diusulkan solusi alternatif sebagai penanganannya. Penanganan konflik adalah langkah-langkah perencanaan untuk menghindari konflik bila memungkinkan dan mengambil langkah-langkah yang cepat dan efektif. Selain itu, untuk menangani konflik, memerlukan penyelidikan dan memverifikasi penyebab konflik dan memberikan tindakan korektif jika diperlukan. Satu hal yang perlu diperhatikan bahwa konflik yang berbeda akan membutuhkan pendekatan yang berbeda pula untuk menyelesaikannya. ${ }^{8}$

Konflik telah menjadi bagian yang alami dan tidak terhindarkan dalam kehidupan manusia. Bisa dipastikan konflik akan selalu muncul selama manusia memiliki tujuan, kepentingan dan pengejaran yang berbeda dalam hidup. Melalui perjalanan waktu manusia harus bergumul setiap hari dengan masalah konflik. Konflik sering dikaitkan dengan konsep yang terkait dengan kepentingan antagonis, kesalahpahaman, persaingan, kepentingan dan tujuan yang secara logis tidak dapat didamaikan, ketegangan yang berlawanan, persaingan, manuver politik, dan perilaku.

Meskipun semua perilaku dan sikap ini mungkin menyertai, memengaruhi, dan memberikan sumber konflik, sebagian besar ilmuwan sosial percaya bahwa tidak satu pun dari istilah-istilah ini yang merupakan sinonim untuk konflik, juga bukan faktorfaktor prasyarat yang memadai untuk konflik. Konflik berkembang ketika perselisihan meningkat di luar kendali pihak-pihak yang terlibat. Unsur-unsur konflik tertanam dalam jiwa manusia. ${ }^{9}$

\footnotetext{
${ }^{8}$ Diin Fitri, "Understanding and Managing Conflict" dalam Journal of Management and Leadership, Vol. 1, No. 1 (2018), h. 1-6.

"Jumoke Adegbonmire, "Conflict Situations and Ways to Resolve Conflicts" dalam ResearchGate (2016), h. 1-36.
} 


\section{Keamanan}

Keamanan menjadi salah satu hal yang didambakan oleh setiap masyarakat dunia. Keamanan juga menjadi tolak ukur bagi suatu negara untuk menjalin hubungan antar negara lainnya. Selain itu dalam hubungan internasional, keamanan menjadi hal yang sering diperhatikan dan dibahas karena dengan terjamin keamanan maka terjamin pula kehidupan masyarakat global.

Kerangka konseptual dari teori keamanan telah menjadi alat yang berguna bagi analis yang ingin menantang gagasan objektivitas ancaman keamanan. Kerangka ini elegan dan telah menghasilkan banyak minat akademis dan memicu sejumlah kritik dan debat, yang bertujuan untuk memperluas dan menentukan lebih lanjut kerangka kerja untuk meningkatkan koherensi logis dan kekuatan penjelasnya. ${ }^{10}$

Keamanan secara hati-hati ditetapkan sebagai isu yang ekstrim dan harus segera ditangani ketika dicap sebagai hal yang berbahaya, mengancam, mengkhawatirkan dan seterusnya oleh aktor keamanan itu sendiri. ${ }^{11}$ Keamanan dipahami sebagai pembentukan wacana hegemoni tentang masalah keamanan. Perlu dipahami bahwa tema atau isu-isu tertentu dapat berfungsi sebagai titik simpul dan penanda, sehingga memungkinkan mereka untuk memimpin rantai kesetaraan dan membentuk wacana hegemoni. Ketersediaan dan kredibilitas berkaitan dengan keamanan dalam arti bahwa penanda tersebut mewakili jenis masalah keamanan yang dapat dipersoalkan, menciptakan wacana keamanan lain dan menempatkan masalah tersebut di ranah di mana tindakan darurat diperlukan.

Masalah keamanan tidak muncul hanya dari analisis kapasitas material relatif, tetapi merupakan konstruksi diskursif. Oleh karena itu kajian teori keamanan membutuhkan penerapan tindakan-tindakan luar biasa dan bahwa keamanan itu merujuk pada dirinya sendiri. Ketika proses keamanan dianalisis sebagai sebuah lapangan, terlihat jelas bahwa modal sosial yang memberdayakan aktor keamanan adalah hasil dari wacana hegemoni yang menganugerahkan kewenangan dan kewajiban untuk

\footnotetext{
${ }^{10}$ Vladimir Šulović, "Meaning of Security and Theory of Securitization" dalam Belgrade Centre for Security Policy (2010), h. 1-7.

${ }^{11}$ Clara Eroukhmanoff, "Securitisation Theory: An Introduction" dalam E-International Relations (2018): 1-4.
} 
melindungi warga negara dari ancaman terhadap keamanan mereka pada negara dan perwakilannya. $^{12}$

Banyak konsep dasar dan definisi teori keamanan memiliki sifat kontroversial seperti keamanan, risiko, ancaman keamanan, jenis keamanan, keamanan informasi, dan lainnya. Mereka dapat diterima dalam praktik, tetapi tidak mencerminkan kekhususan saat ini dan memerlukan pertimbangan ulang dan penyempurnaan penuh dengan pandangan ilmiah modern.

\section{Metode Penelitian}

Metode yang digunakan ialah metode pemantauan cepat meliputi wawancara kepada informan kunci dan observasi langsung. Metode penilaian cepat harus digunakan secara selektif dan situasi diidentifikasi di mana penerapannya secara khusus sesuai dengan fenomena yang diteliti. Penilaian cepat adalah pendekatan untuk mengembangkan pemahaman awal tentang suatu situasi. Penelitian ini dilakukan pada tahun 2014, namun beberapa data telah diperbarui kembali.

\section{Sejarah Konflik di Kabupaten Pontianak}

\section{Konflik Perbatasan}

Tabel di dibawah ini merupakan hasil penelitian lapangan mengenai konflik yang pernah terjadi di Kabupaten Pontianak berkaitan dengan batas wilayah.

Tabel 2.

Konflik Perbatasan di Kabupaten Pontianak

\begin{tabular}{|l|l|l|}
\hline No. & \multicolumn{1}{|c|}{ Lokasi } & \multicolumn{1}{c|}{ Konflik } \\
\hline 1. & $\begin{array}{l}\text { Kabupaten } \\
\text { Pontianak }\end{array}$ & $\begin{array}{l}\text { Masyarakat Desa Sungai Purun Besar dengan masyarakat } \\
\text { Desa Peniti Besar Kecamatan Segedong }\end{array}$ \\
\hline 2. & Kabupaten Landak & $\begin{array}{l}\text { Masyarakat Desa Sei Purun Besar, Kecamatan Segedong, } \\
\text { Kabupaten Pontianak dan Dusun Sinam, Desa Ngarak, } \\
\text { Kecamatan Mandor }\end{array}$ \\
\hline
\end{tabular}

Sumber: Polres Kabupaten Pontianak

${ }^{12}$ Marcos Cardoso dos Santos, "Identity and Discourse in Securitisation Theory" dalam Contexto Internacional, Vol. 40, No. 2 (2018), h. 229-248. 
Konflik terjadi dalam bentuk sengketa tanah, konflik investasi, dan konflik politik, sehingga perlu dicari alternatif pengelolaan agar tidak menimbulkan konflik yang berujung pada kekerasan. Kasus batas wilayah muncul disebabkan gugatan/sanggahan dari masyarakat baik secara perseorangan maupun oleh lembaga. Hasil penelitian menemukan bahwa sengketa tanah terjadi karena masalah kepemilikan ganda dari sertifikat lahan. Akibatnya, secara legal banyak lahan bersertifikat yang mungkin dimiliki oleh perusahaan besar atau investor, karena dibeli dari petani/pemilik lahan, namun lahan tersebut sudah lama ditinggalkan.

\section{Konflik Investasi-Perkebunan}

Kabupaten Pontianak merupakan kabupaten yang memiliki prospek investasi. Hal ini dikarenakan kaya akan sumber daya alam sehingga menarik minat perusahaanperusahaan besar untuk menanamkan modalnya dalam pengolahan sumber daya alam. Namun di sisi lain, investasi besar-besaran dari berbagai korporasi justru melahirkan konflik baru.

Tabel 2.

Konflik Investasi-Perkebunan di Kabupaten Pontianak

\begin{tabular}{|c|c|c|}
\hline No. & Lokasi & Konflik \\
\hline 1 & $\begin{array}{l}\text { Desa Bangkam, } \\
\text { Bukit Batu }\end{array}$ & $\begin{array}{l}\text { Konflik warga dengan PT. Multi-Mighty Strada } \\
\text { (SMP) di Desa Bangkam, Bukit Batu rusak dan tidak } \\
\text { memberikan kontribusi kepada daerah }\end{array}$ \\
\hline 2 & Desa Wajok Hulu & $\begin{array}{l}\text { Konflik antar warga Desa Wajok Hulu menolak PT. } \\
\text { MAS }\end{array}$ \\
\hline 3 & Desa Peniraman & $\begin{array}{l}\text { Konflik Lahan Warga Desa Peniraman Vs PT. } \\
\text { Hartono Plantiton Indonesia }\end{array}$ \\
\hline 4 & Desa Peniraman & $\begin{array}{l}\text { Tindak kekerasan terhadap masyarakat Desa } \\
\text { Peniraman oleh PT. Peniti Sungai Purun }\end{array}$ \\
\hline 5 & Kabupaten Landak & Kebakaran di Perusahaan Kelapa Sawit PT. Djarum \\
\hline 6 & $\begin{array}{l}\text { Kecamatan } \\
\text { Anjongan }\end{array}$ & $\begin{array}{l}\text { Konflik antara warga Dusun Kepayang, Desa } \\
\text { Anjongan, Kelurahan Anjongan, dan PT. Perkebunan } \\
\text { Tanjung Indah }\end{array}$ \\
\hline 7 & $\begin{array}{l}\text { Desa Pasir Wan } \\
\text { Salim }\end{array}$ & $\begin{array}{l}\text { Warga Kecamatan Pasir Wan Salim, Kec. Kabupaten } \\
\text { Mempawah Timur. Pontianak Permasalahan terkait } \\
\text { Polusi Kebisingan / Kebisingan dari mesin PLN }\end{array}$ \\
\hline
\end{tabular}

Sumber: Polres Kabupaten Pontianak 
Selama 2014 tercatat telah terjadi sebanyak 82 sengketa lahan. Hingga pada term pertama tahun 2016 terjadi 40 sengketa lahan. Diketahui bahwa penyebab konflik tersebut lebih banyak disebabkan oleh perampasan tanah pertanian masyarakat untuk dialihfungsikan sebagai kawasan industri. ${ }^{13}$ Sengketa lahan sendiri disebabkan oleh kendala hukum atas akses, distribusi yang tidak merata di antara pengguna, atau kekurangan total lahan sehubungan dengan permintaan, serta kelangkaan yang menyebabkan banyak orang memiliki sedikit atau tanpa lahan dan menciptakan persaingan yang ketat untuk mendapatkan lahan.

Perkebunan dan pengolahan kelapa sawit telah menjadi industri komoditas primer yang strategis bagi negara-negara seperti Indonesia dan beberapa negara di Asia Tenggara. Kehadiran perkebunan telah menimbulkan konflik dan mengakibatkan perubahan berbagai sikap dan perilaku masyarakat serta dampak lingkungan yang mengganggu aktivitas masyarakat sekitar. Beberapa dampak negatif dari industri kebun sawit menunjukkan bahwa pendekatan yang dilakukan selama ini masih perlu ditingkatkan.

\section{Konflik Politik}

Berdasarkan hasil penelitian para peneliti, Kabupaten Pontianak mencatat sejarah politik yang sangat panas di Kalimantan Barat pada tahun 1999. Saat itu Kabupaten Pontianak masih belum terpecah menjadi wilayah administratif. Namun setelah 1999, konflik politik di Pontianak tidak kunjung selesai. Masih ada potensi yang bisa memicu konflik, seperti isu Pemilihan Kepala Daerah (Pilkada) dan Pemilihan Legislatif.

Selama proses dan pelaksanaan Pilkada Pontianak tahun 2013, terdapat 9 laporan dugaan pelanggaran. Salah satunya adalah pelanggaran politik uang yang mendominasi pelanggaran Pilkada pasca-konflik di Kabupaten Pontianak. Dugaan pelanggaran tersebut dilaporkan ke Pengawas Pemilu Kabupaten Pontianak. Selain itu, ada juga laporan pemberian barang. Pemberian barang dan uang dilatarbelakangi untuk mempengaruhi dukungan rakyat dalam pesta demokrasi yang sedang berlangsung.

\footnotetext{
${ }^{13}$ Severianus Endi, "Konflik Dengan Perusahaan Sawit, Warga Mengadu Ke Komnas HAM" dalam https://www.benarnews.org/indonesian/berita/konflik-lahan-sawit-08022016171614.html diakses 1 Januari 2021.
} 
Hasil penelitian menemukan bahwa potensi konflik di Kabupaten Pontianak bisa meledak sewaktu-waktu jika tidak dideteksi sejak dini. Meskipun tingkat partisipasi politik masyarakat terbilang cukup tinggi pada Pilkada dan Pemilihan Legislatif, namun isu ras, suku dan agama dikhawatirkan akan memicu konflik baru di kemudian hari.

\section{Penanganan Konflik Menuju Keamanan Melalui Aktor Keamanan}

\section{Budaya Lokal}

Budaya lokal di beberapa komunitas lokal di Indonesia dalam mengakses sumber daya alam menjadi tantangan besar bagi pengambil kebijakan untuk mencapai pembangunan berkelanjutan. ${ }^{14}$ Hasil penelitian menunjukkan bahwa Kabupaten Pontianak saat ini akan menjadi rawan, jika pemerintah daerah dan pembuat kebijakan terus memilah atau membedakan antar kelompok atau agama sebagaimana terjadi pada tahun 1999. Namun demikian, jika pemerintah daerah bersedia memfasilitasi masyarakat yang majemuk, dengan memberikan ruang dan membangun dialog antar sesama masyarakat Kabupaten Pontianak lintas suku, adat istiadat, dan agama, potensi konflik ini dapat diredam.

Budaya ialah salah satu komponen yang diupayakan sebagai media menyelesaikan perselisihan yang pernah terjadi di Kalimantan Barat, termasuk Kabupaten Pontianak. Berbagai komunitas adat bertugas menjaga, melindungi dan menjaga keutuhan keseimbangan ekosistem sosial bahkan termasuk pencegahan konflik politik sebagai perawatan keamanan di masyarakat.

Keamanan telah dikembangkan dan diperjuangkan secara berkelanjutan tanpa batas waktu dan tanpa lelah. Keamanan tidak berarti membuat orang menghindari konflik, atau dari perbedaan, melainkan menghargai perbedaan seperti perbedaan ras, etnis, agama dan politik. ${ }^{15}$ Keamanan adalah harapan setiap manusia. Sebagai masyarakat yang terbuka terhadap perkembangan zaman, tentunya mendambakan keamanan. Dengan adanya keamanan di tengah-tengah masyarakat maka masyarakat dapat leluasa beraktifitas dengan damai.

\footnotetext{
${ }^{14}$ Nida Humaida, Virgina Maria Louisa \& Nana Citrawati Lestari, "Characteristics of The Local Wisdom from South Borneo In Ecological Aspect" dalam ESE International Journal, Vol. 1, No. 2 (2018), h. 30-34.

${ }^{15}$ Lester R. Kurtz (ed.), Encyclopedia of Violence, Peace, and Conflict (Cambridge, Massachusetts: Academic Press, 2008).
} 


\section{Peran Tokoh dan Lembaga Lokal}

Tokoh masyarakat Kabupaten Pontianak, seperti tokoh agama, tokoh masyarakat, dan tokoh adat memiliki kedudukan dan pengaruh yang besar di masyarakatnya, karena memiliki kelebihan, baik secara ilmu, kedudukan, keturunan dan lain sebagainya. Pemimpin komunitas informal adalah pemimpin informal dalam komunitasnya yang diangkat baik atas kemauan ataupun atas persetujuan komunitasnya. ${ }^{16}$ Tokoh informal masyarakat Pontianak yang dimaksud adalah tokoh masyarakat yang memiliki integritas tinggi, memegang teguh pendapat dan keyakinannya, namun terbuka untuk bisa menerima perbedaan secara arif di Kabupaten Pontianak.

Selain diharapkan dapat mempengaruhi umatnya, secara kultural juga diharapkan memiliki kekuatan nyata yang dapat menggerakkan masyarakat menuju tujuan yang luhur, yaitu: membangun saling pengertian, kebersamaan, kerjasama, dan solidaritas internal, serta antaragama yang beragama. Peran tokoh masyarakat informal telah mampu mendorong agar fungsi sosial agama yang dilaksanakan dalam kehidupan sehari-hari dapat meningkatkan kerukunan kehidupan beragama dalam rangka ketahanan nasional. Hasil penelitian menunjukkan bahwa peran semua pemangku kepentingan dalam menjaga dan membangun keamanan di Kabupaten Pontianak seperti pemerintah daerah, tokoh agama, tokoh adat, polisi juga sudah terlibat dalam segala hal.

\section{Peran Aktor Keamanan}

Pengembangan partisipasi masyarakat dalam membina keamanan, ketertiban, dan terwujudnya kerjasama antar aparat keamanan penting dilakukan dengan melibatkan seluruh elemen masyarakat di Kabupaten Pontianak. Hal tersebut dilakukan dengan membina dan mengembangkan bentuk keamanan swadaya dalam rangka peningkatan kesadaran masyarakat dan kepatuhan terhadap peraturan perundangundangan.

Hasil penelitian menemukan bahwa Polri terlihat standby dalam segala hal. Oleh karena itu, Polri telah memposisikan diri sebagai mediator (penegak) bukan pemecah

\footnotetext{
${ }^{16}$ Hendy Mustiko Aji, Istyakara Muslichah \& Cahyo Seftyono, "The Determinants of Muslim Travellers Intention to Visit Non-Islamic Countries: A Halal Tourism Implication" dalam Journal of Islamic Marketing, Vol. 12 No. 8 (2021), h. 1553-1576.
} 
masalah, misalnya dalam menyelesaikan konflik antara masyarakat dengan perusahaan misalnya dan telah mengundang instansi terkait untuk duduk bersama mencari solusi yang baik dan tidak saling merugikan.

Selain institusi kepolisian yang berperan dalam menciptakan keamanan, juga institusi TNI diharapkan dapat bersinergi dengan institusi kepolisian. Pada prinsipnya TNI bertanggung jawab atas keutuhan Indonesia. Oleh karena itu, sejauh ini terbukti mampu melakukan pengamanan dan pencegahan konflik. Misalnya di Kabupaten Pontianak, TNI banyak terlibat dalam pengamanan, seperti pada saat Pilkada.Selain itu, institusi TNI juga dituntut untuk tetap dalam posisi netral menghadapi Pilkada di Pontianak. Hal itu dilakukan untuk menepis dan tidak mendukung salah satu calon kepala daerah walaupun ada pensiunan yang ikut sebagai kandidat kepala daerah di Kabupaten Pontianak.

\section{Penutup}

Kabupaten Pontianak dapat dikategorikan sebagai salah satu daerah rawan konflik di Kalimantan Barat, apalagi secara historis Kabupaten Pontianak pernah mengalami konflik komunal yang eskalasinya cukup tinggi. Di Indonesia tidak terkecuali di Kabupaten Pontianak, secara umum akar penyebab konflik komunal biasanya disebabkan oleh faktor laten seperti kemiskinan, ketimpangan ekonomi, elite capture, dan ketidakmampuan pemerintah daerah dalam mengelola sumber daya fiskal. Oleh karena itu, diperlukan kebijakan pembangunan yang tepat untuk menghindari konflik yang berujung pada kekerasan. Penyelesaian konflik yang dilakukan akhir-akhir masih belum berkelanjutan. Mengingat Kabupaten Pontianak terdiri dari sembilan kabupaten yang dihuni oleh berbagai suku bangsa dengan ragam budaya, tradisi, dan pemeluk agama yang beraneka ragam. Pemanfaatan kearifan lokal sangat penting bagi masyarakat dalam upaya menyelesaikan konflik di tengah-tengah masyarakat.

\section{DAFTAR PUSTAKA}

Adegbonmire, Jumoke. "Conflict Situations and Ways to Resolve Conflicts" dalam ResearchGate (2016), h. 1-36.

Aji,Hendy Mustiko, Istyakara Muslichah \& Cahyo Seftyono."The Determinants of Muslim Travellers Intention to Visit Non-Islamic Countries: A Halal Tourism 
Implication" dalam Journal of Islamic Marketing, Vol. 12 No. 8 (2021), h. 1553-1576.

Brück, Tilman, Wim Naudé \& Philip Verwimp. "Business Under Fire: Entrepreneurship and Violent Conflict in Developing Countries" dalam Journal of Conflict Resolution, Vo. 57, No. 1 (2012), h. 3-19.

Cederman, Lars-Erik \& Yannick Pengl. "Global Conflict Trends and Their Consequences" dalam Background Paper to the United Nations Sustainable Development Outlook (2019), h. 1-55.

Eroukhmanoff, Clara. "Securitisation Theory: An Introduction" dalam E-International Relations (2018): 1-4.

Fitri, Diin. "Understanding and Managing Conflict" dalam Journal of Management and Leadership, Vol. 1, No. 1 (2018), h. 1-6.

Hassan, Mabroor, Manzoor Khan Afridi \& Muhammad Irfan Khan. "Environmental Diplomacy in South Asia: Considering the Environmental Security, Conflict and Development Nexus" dalam Geoforum, Vol. 82 (2017), h. 127-130.

Humaida, Nida, Virgina Maria Louisa \& Nana Citrawati Lestari. "Characteristics of The Local Wisdom from South Borneo In Ecological Aspect" dalam ESE International Journal, Vol. 1, No. 2 (2018), h. 30-34.

Kansanga, Moses Mosonsieyiri, Godwin Arku \& Isaac Luginaah. "Powers of Exclusion and Counter-Exclusion: The Political Ecology of Ethno-Territorial Customary Land Boundary Conflicts in Ghana" dalam Land Use Policy, Vol. 86, Issue C (2019), h. 12-22.

Kristianus. "Nasionalisme Etnik Di Kalimantan Barat" dalam Masyarakat Indonesia, Vol. 37, No. 2 (2011), h. 147-176.

Kurtz, Lester R. (ed.). Encyclopedia of Violence, Peace, and Conflict. Cambridge, Massachusetts: Academic Press, 2008.

Martoyo, Elyta, Herlan Herlan \& Arifin Arifin. "Economic Development and Sustainable Human Resources by Supply Chain Managament in Government Towards in West Kalimantan Indonesia" dalam International Journal Of Supply Chain Managament, Vol. 9, No. 1 (2020), h. 1054-1063.

Santos, Marcos Cardoso dos. "Identity and Discourse in Securitisation Theory" dalam Contexto Internacional, Vol. 40, No. 2 (2018), h. 229-248. 
Sujarwoto. "Geography and Communal Conflict in Indonesia" dalam Indonesian Journal of Geography, Vol. 49, No. 1 (2017), h. 89-96.

Šulović, Vladimir. "Meaning of Security and Theory of Securitization" dalam Belgrade Centre for Security Policy (2010), h. 1-7.

\section{Website}

Endi, Severianus. "Konflik Dengan Perusahaan Sawit, Warga Mengadu Ke Komnas HAM" dalam https://www.benarnews.org/indonesian/berita/konflik-lahan-sawit08022016171614.html diakses 1 Januari 2021. 